\title{
FRACTURE STRENGTH OF DIFFERENT SOLDERED AND WELDED ORTHODONTIC JOINING CONFIGURATIONS WITH AND WITHOUT FILLING MATERIAL
}

\author{
Jens Johannes BOCK ${ }^{1}$, Jacqueline BAILLY ${ }^{2}$, Christian Ralf GERNHARDT ${ }^{3}$, Robert Andreas Werner FUHRMANN ${ }^{4}$
}

1- Dr. med. Dent., DDS, Assistant Professor, Department of Orthodontics, Martin-Luther-University Halle-Wittenberg, Germany.

2- DDS, Department of Orthodontics, Martin-Luther-University Halle-Wittenberg.

3- Dr. med. Dent., DDS, Assistant Professor, Department of Operative Dentistry and Periodontology, Martin-Luther-University Halle-Wittenberg, Germany.

4- Prof. Dr. med. Dr. med. Dent., DDS, Professor and Chair, Department of Orthodontics, Martin-Luther-University Halle-Wittenberg, Germany.

Corresponding address: Dr. Christian R. Gernhardt - Martin-Luther-University Halle-Wittenberg - Department of Operative Dentistry and Periodontology - University School of Dental Medicine - Grosse Steinstrasse 19 - 06097 Halle/Saale, Germany - Phone: +049345/5573741 Fax: +049345/5573773 - e-mail: christian.gernhardt@medizin.uni-halle.de

Received: March 11, 2008 - Modification: April 18, 2008 - Accepted: April 18, 2008

\begin{abstract}
T

he aim of this study was to compare the mechanical strength of different joints made by conventional brazing, TIG and laser welding with and without filling material. Five standardized joining configurations of orthodontic wire in spring hard quality were used: round, cross, $3 \mathrm{~mm}$ length, $9 \mathrm{~mm}$ length and $7 \mathrm{~mm}$ to orthodontic band. The joints were made by five different methods: brazing, tungsten inert gas (TIG) and laser welding with and without filling material. For the original orthodontic wire and for each kind of joint configuration or connecting method 10 specimens were carefully produced, totalizing 240. The fracture strengths were measured with a universal testing machine (Zwick 005). Data were analyzed by ANOVA ( $\mathrm{p}=0.05)$ and Bonferroni post hoc test $(\mathrm{p}=0.05)$. In all cases, brazing joints were ruptured on a low level of fracture strength (186-407 N). Significant differences between brazing and TIG or laser welding ( $\mathrm{p}<0.05$, Bonferroni post hoc test) were found in each joint configuration. The highest fracture strength means were observed for laser welding with filling material and $3 \mathrm{~mm}$ joint length (998 N). Using filling materials, there was a clear tendency to higher mean values of fracture strength in TIG and laser welding. However, statistically significant differences were found only in the 9-mm long joints $(\mathrm{p}<0.05$, Bonferroni post hoc test). In conclusion, the fracture strength of welded joints was positively influenced by the additional use of filling material. TIG welding was comparable to laser welding except for the impossibility of joining orthodontic wire with orthodontic band.
\end{abstract}

Key words: Soldering. Brazing. Laser welding. Tungsten inert gas welding. Welding with filling material.

\section{INTRODUCTION}

In conventional dental brazing - defined as soldering over a temperature of $450^{\circ} \mathrm{C}$ - the parent metals are joined with different types of metals, which may reduce corrosion resistance because of galvanic corrosion between metals ${ }^{5-}$ ${ }^{7}$. The high corrosion rates can influence the biocompatibility. The results of Solmi, et al. ${ }^{14}$ (2004) highlighted the superior biological quality of laser-welding over brazing. Other authors characterized orthodontic materials as non cytotoxic except for silver soldered joints ${ }^{10}$. While testing the cell reactions of osteoblasts, fibroblasts and keratinocytes, Sestini. et al. ${ }^{13}$ (2006) found a good tolerance of electrical resistance and laser welding, while traditional silver solder was toxic for osteoblast differentiation, fibroblast viability and keratinocyte growth.

The strength of silver soldered joints used to fabricate space maintainers and orthodontic appliances is critical to their success ${ }^{10,12,13,28-30}$.

Another method employed for joining metal frameworks is laser welding ${ }^{1-4,8,17-20}$. In order to weld dental alloys, crystals of yttrium aluminum garnet (YAG) doped with neodymium (Nd) are mainly used to emit laser beams (Nd:YAG laser $)^{9,11,15,21,22,26}$. The factors affecting the mechanical strength of laser welded joints are the wave length, peak pulse power, pulse energy, output energy, pulse duration, pulse frequency, and spot diameter of the laser-welding machine, and the type of metal used ${ }^{9,11,15,21}$. Many laser welding machines used in dentistry have variable settings for output energy (voltage or current), spot diameter and pulse duration. Different combinations of these conditions can change the penetration depth of the laser into the metals and affect the joint strength of the laser welded restoration ${ }^{9,11,15,21,24}$. 


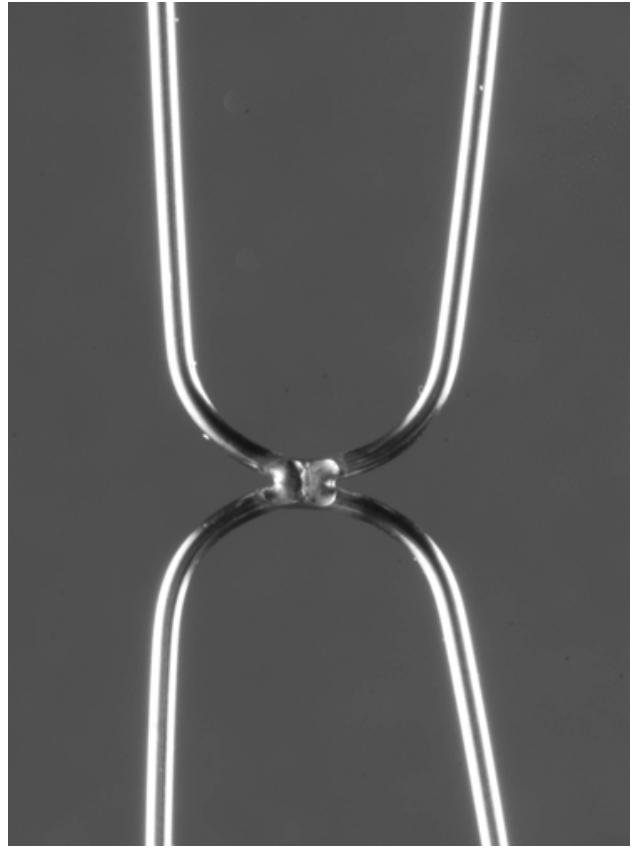

FIGURE 1- Round joints. Wire material: Forestanit in spring hard quality (diameter $0.9 \mathrm{~mm}$ )

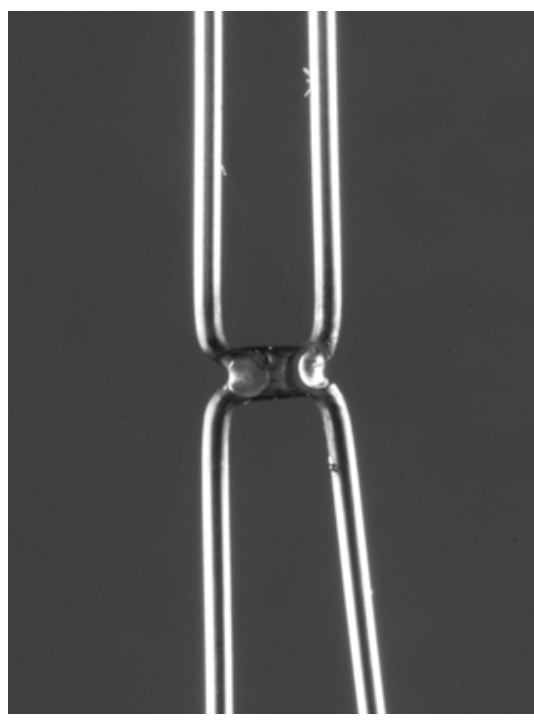

FIGURE 3- 3-mm long joints. Wire material: Forestanit in spring hard quality (diameter $0.9 \mathrm{~mm}$ )

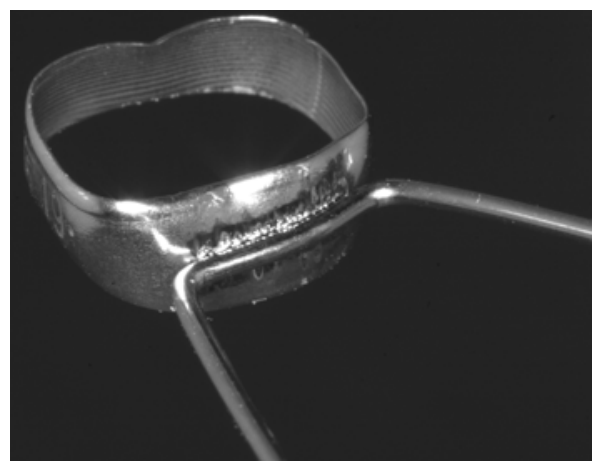

FIGURE 5- Band-to-wire joints. Wire material: Forestanit in spring hard quality (diameter $0.9 \mathrm{~mm}$; length $7 \mathrm{~mm}$ ). Band material: Dura-Fit (Forestadent. Germany)

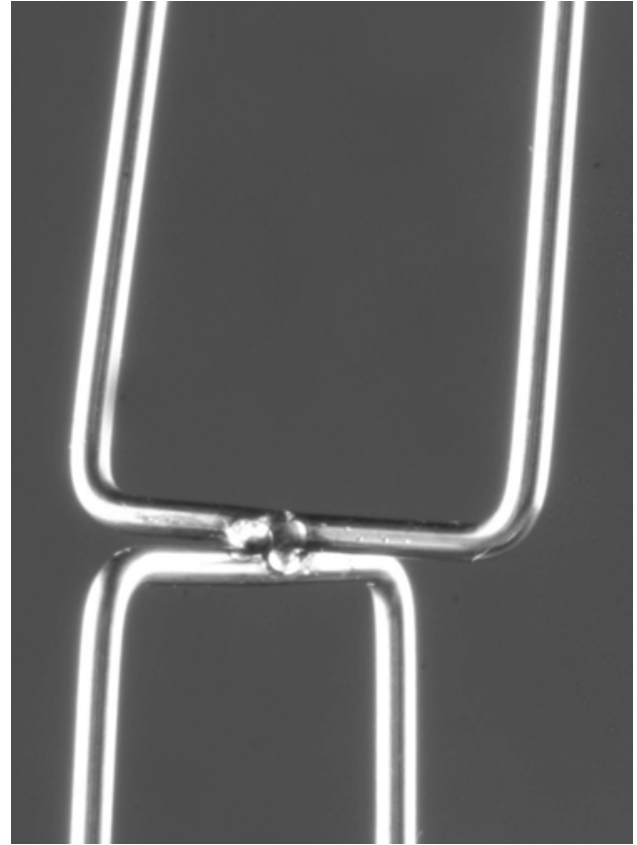

FIGURE 2- Cross joints. Wire material: Forestanit in spring hard quality (diameter $0.9 \mathrm{~mm}$ )

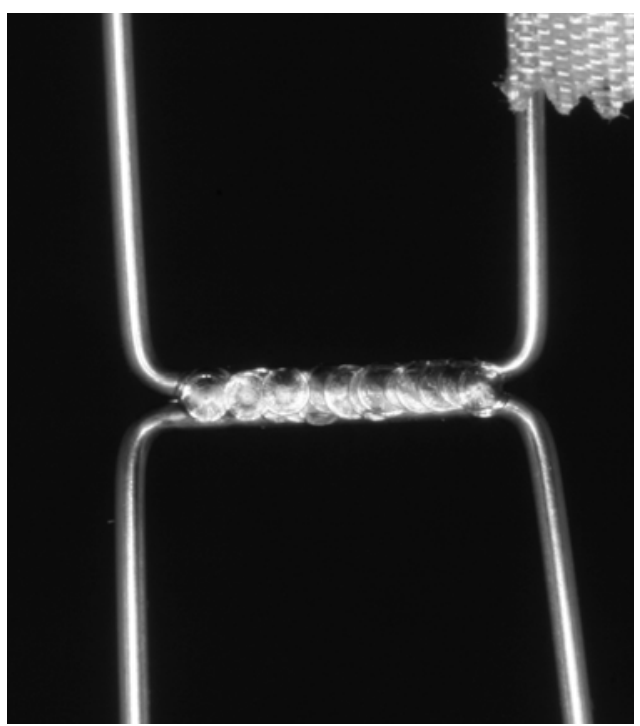

Figure 4- 9-mm long joints. Wire material: Forestanit in spring hard quality (diameter $0.9 \mathrm{~mm}$ )

In 2005, an interesting lower cost alternative was introduced in orthodontics. Two different devices for orthodontic purposes were developed based on tungsten inert gas (TIG) welding, a well known arc welding process. The welding heat is produced with the aid a light bow between tungsten anode and metal.

Laser and TIG welding can weld parent metals without solder or with material consisting of the same parent metal ${ }^{16}$. Therefore, the corrosion resistance may be increased because the same metal is used. Due to their advantages, laser and TIG- welding may be beneficial for joining in orthodontic purposes. Currently, only little information concerning the mechanical strength of these joints is 
available in dental literature. Therefore, the aim of this study was to compare the mechanical strength of joints made by conventional brazing, TIG and laser welding with and without filling material.

\section{MATERIALAND METHODS}

Five standardized joint configurations of the orthodontic wire material Forestanit (LOT: 272; Forastadent, Pforzheim, Germany) in spring hard quality ( $0.9 \mathrm{~mm}$ diameter for all joints, $0.5 \mathrm{~mm}$ diameter for filling material) was used (Figures 1 to 5). The joints were made by 5 different methods: brazing with universal silver solder, TIG welding with and without filling material (Welder, Schütz Dental, Germany) and laser welding with and without filling material (LWI, Schütz Dental). Laser parameters and welding conditions followed the manufacturer's recommendations (Table 1). For each joining method, 10 specimens were carefully produced. The tensile strength of the original wire material with the diameters of $0.9 \mathrm{~mm}(\mathrm{n}=10)$ were also measured. A total of 240 specimens were tested.

Measurements of joint length took place at x34 magnification with the aid of a computer-assisted video inspection system VMZM/40 (Jena Engineering Company, Germany).

Fracture strength measurement of different welding and brazing methods was carried out using a universal testing machine (Zwick 005. Machine, ZR Sverige, Kullavik, Sweden). The wire length between the cross-heads of the machine was standardized as $5 \mathrm{~mm}$. The full scale load was set at $2000 \mathrm{~N}$ with a crosshead speed of $10 \mathrm{~mm} / \mathrm{min}$. The recorded data were analyzed using SPSS 12.0 statistical software package (SPSS Inc., Chicago, IL, USA). Statistical analysis was undertaken by one-way analysis of variance (Anova, $\mathrm{p}=0.05$ ) and Bonferroni post hoc test $(\mathrm{p}=0.05)$.

\section{RESULTS}

Means, minima, maxima and standard deviations of the joint length are given in Table 2. No significant differences between the various joint configurations except for the connections of band to orthodontic wire were found (ANOvA, $\mathrm{p}<0.05$ ) (Table 3). In this configuration, the mean joint length made by brazing was between 0.5 and $1.0 \mathrm{~mm}$ longer than in Laser 1 or Laser 2.

Means, minima, maxima and standard deviations of the fracture strength of the different joining method are given in Table 4. Mean tensile strengths of the original orthodontic wire $(n=10$, diameter $0.9 \mathrm{~mm}: 1492 \pm 55 \mathrm{~N})$ were found in accordance with the manufacturer's instructions. Compared to these findings welding and brazing significantly decreased the fracture strength (AnOva, $\mathrm{p}<0.001$ ) (Table 4).

According to manufacturer's guidance, TIG-welding of orthodontic wire to orthodontic band could not been carried out.

For brazing, the highest fracture strength means were observed in the band-to-wire configuration (406.7 \pm 116.1 $\mathrm{N})$. The lowest means for brazing were found in the cross joints $(185.9 \pm 36.0 \mathrm{~N})$.

For TIG-welding, the highest fracture strength means were observed in the 3-mm-long joints with filling material (TIG 2: $866.1 \pm 136.9 \mathrm{~N}$ ). The lowest fracture strength means were shown in the 9-mm-long joints (TIG 1: $548.9 \pm 105.3 \mathrm{~N}$ ). Except for the cross joints, higher fracture strength means were found for TIG welding with filling material.

In the present study, the absolute highest fracture strength means were found in laser welding to joining orthodontic wire of $3 \mathrm{~mm}$ length with additional use of filling material (Laser 2: $997.9 \pm 281.7 \mathrm{~N}$ ). The lowest fracture strength means in laser welding were found in the configuration orthodontic wire to band without filling material (Laser 1: $328.8 \pm 31.7 \mathrm{~N}$ )

The Anova results are shown in Table 5. In general, statistically significant differences $(\mathrm{p}<0.05)$ were found among the various joining configurations and soldered or welded specimens.

Statistical comparison of single groups demonstrated a significant decrease of fracture strength means in brazing related to TIG- or laser welding except for the band to wire joints (Bonferroni post hoc test, $\mathrm{p}<0.001$ ) (Table 6).

Using additional filling materials higher fracture strength means were achieved with both TIG- or laser welding. Statistically significant differences (Bonferroni post hoc test, $\mathrm{p}<0.05$ ) were found between the 9-mm-long joints produced by TIG- or laser welding with and without filling materials (Table 6).

Except for the joints of $9 \mathrm{~mm}$ and the band- to-wire configuration, no significant differences (Bonferroni post hoc test, $\mathrm{p}>0.05$ ) were found between Laser 1 and Laser 2 (Table 6). Concerning the band-to-wire joints, the mean values of fracture strength did not differ significantly between Laser 1 and brazing, but a slight tendency to lower means in laser welding without filling material was found (Bonferroni post hoc test, p $>0.05$ (Table 6). Significantly higher fracture strength means of the band-to-wire joints were shown in laser welding with filling material.

\section{DISCUSSION}

Studies about mechanical behavior of welded or soldered orthodontic wires are rare. Up to date, a direct comparison of different brazing and welding methods is missing and the influence of different TIG- or laser welding devices cannot be estimated. No scientific studies were found to evaluate the effects of filling material on the fracture strength of TIGor laser welded orthodontic wires.

The results of fracture strength measurements of welded precious and non-precious cast alloys used in fixed or removable prosthodontics can be transferred to orthodontic purposes only with strong limitations ${ }^{8,10}$. Special considerations of the wire materials are required to fulfill clinical criteria in orthodontics ${ }^{19}$.

The influences of brazing or welding on fracture strength 
FRACTURE STRENGTH OF DIFFERENT SOLDERED AND WELDED ORTHODONTIC JOINING CONFIGURATIONS WITH AND WITHOUT FILLING MATERIAL

TABLE 1- Brazing and welding conditions used in the study. TIG=Tungsten-Inert gas welding. Laser= laser welding

\begin{tabular}{|c|c|c|c|}
\hline Brazing & \multicolumn{2}{|c|}{ Silver solder (LOT.: 47160) } & Dentaurum (Ispringen, Germany) \\
\hline \multirow[t]{2}{*}{ TIG 1} & \multicolumn{2}{|c|}{ Welder without filling material } & Schütz Dental (Rosbach, Germany) \\
\hline & Fig. 1-4: & $\mathrm{P} 4,30 \mathrm{~ms}$ & \\
\hline \multirow[t]{2}{*}{ TIG 2} & \multicolumn{2}{|c|}{ Welder with filling material } & Schütz Dental (Rosbach, Germany) \\
\hline & Fig. 1-4: & $\mathrm{P} 4,30 \mathrm{~ms}$ & \\
\hline \multirow[t]{3}{*}{ Laser 1} & \multicolumn{2}{|c|}{ LWI without filling material } & Schütz Dental (Rosbach, Germany) \\
\hline & Fig. 1-4: & $\mathrm{P} 2,5 \mathrm{~ms}, 0.9 \mathrm{~mm}$ & \\
\hline & Fig. 5: & $\mathrm{P} 1,1 \mathrm{~ms}, 0.4 \mathrm{~mm}$ & \\
\hline \multirow[t]{3}{*}{ Laser 2} & \multicolumn{2}{|c|}{ LWI with filling material } & Schütz Dental (Rosbach, Germany) \\
\hline & Fig. 1-4: & $\mathrm{P} 2,5 \mathrm{~ms}, 0.9 \mathrm{~mm}$ & \\
\hline & Fig. 5: & $\mathrm{P} 1,1 \mathrm{~ms}, 0.4 \mathrm{~mm}$ & \\
\hline
\end{tabular}

TIG=Tungsten-Inert gas welding. Laser= laser welding.

TABLE 2- Means, standard deviation (SD), standard error (SE), minimum and maximum of length (mm) of the used soldered and welded specimens

\begin{tabular}{|c|c|c|c|c|c|c|c|}
\hline \multicolumn{2}{|c|}{ Joining configuration } & \multirow{2}{*}{$\frac{\mathbf{n}}{10}$} & \multirow{2}{*}{$\begin{array}{l}\text { Means } \\
2.37\end{array}$} & \multirow{2}{*}{$\begin{array}{l}\text { SD } \\
0.21\end{array}$} & \multirow{2}{*}{$\begin{array}{l}\text { SE } \\
0.07\end{array}$} & \multirow{2}{*}{$\begin{array}{c}\text { minimum } \\
2.04\end{array}$} & \multirow{2}{*}{$\frac{\text { maximum }}{2.73}$} \\
\hline round & solder & & & & & & \\
\hline & TIG 1 & 10 & 2.39 & 0.37 & 0.12 & 1.85 & 2.88 \\
\hline & TIG 2 & 10 & 2.46 & 0.16 & 0.05 & 2.24 & 2.71 \\
\hline & Laser 1 & 10 & 2.18 & 0.23 & 0.07 & 1.91 & 2.55 \\
\hline & Laser 2 & 10 & 2.38 & 0.15 & 0.05 & 2.22 & 2.64 \\
\hline & overall & 50 & 2.36 & 0.25 & 0.04 & 1.85 & 2.88 \\
\hline \multirow[t]{6}{*}{ cross } & solder & 10 & 0.90 & 0.04 & 0.01 & 0.83 & 0.99 \\
\hline & TIG 1 & 10 & 0.85 & 0.04 & 0.01 & 0.80 & 0.92 \\
\hline & TIG 2 & 10 & 0.88 & 0.10 & 0.03 & 0.79 & 1.13 \\
\hline & Laser 1 & 10 & 0.84 & 0.03 & 0.01 & 0.80 & 0.90 \\
\hline & Laser 2 & 10 & 0.89 & 0.02 & 0.01 & 0.86 & 0.92 \\
\hline & overall & 50 & 0.87 & 0.06 & 0.01 & 0.79 & 1.13 \\
\hline \multirow[t]{6}{*}{$3 \mathrm{~mm}$} & solder & 10 & 3.31 & 0.17 & 0.06 & 3.07 & 3.64 \\
\hline & TIG 1 & 10 & 3.22 & 0.22 & 0.07 & 2.95 & 3.55 \\
\hline & TIG 2 & 10 & 3.22 & 0.17 & 0.06 & 3.01 & 3.45 \\
\hline & Laser 1 & 10 & 3.06 & 0.17 & 0.05 & 2.85 & 3.29 \\
\hline & Laser 2 & 10 & 3.29 & 0.20 & 0.06 & 3.04 & 3.62 \\
\hline & overall & 50 & 3.22 & 0.20 & 0.03 & 2.85 & 3.64 \\
\hline \multirow[t]{6}{*}{$9 \mathrm{~mm}$} & solder & 10 & 9.56 & 0.29 & 0.09 & 9.25 & 10.18 \\
\hline & TIG 1 & 10 & 9.31 & 0.31 & 0.10 & 9.01 & 9.88 \\
\hline & TIG 2 & 10 & 9.26 & 0.34 & 0.11 & 8.73 & 9.89 \\
\hline & Laser 1 & 10 & 9.41 & 0.56 & 0.18 & 8.19 & 9.96 \\
\hline & Laser 2 & 10 & 9.48 & 0.16 & 0.05 & 9.14 & 9.71 \\
\hline & overall & 50 & 9.40 & 0.36 & 0.05 & 8.19 & 10.18 \\
\hline \multirow[t]{4}{*}{ band } & solder & 10 & 7.36 & 0.35 & 0.12 & 6.85 & 7.92 \\
\hline & Laser 1 & 10 & 6.38 & 0.46 & 0.15 & 5.81 & 7.35 \\
\hline & Laser 2 & 10 & 6.57 & 0.39 & 0.12 & 6.04 & 7.44 \\
\hline & overall & 30 & 6.75 & 0.58 & 0.11 & 5.81 & 7.92 \\
\hline
\end{tabular}


TABLE 3- Results of ANOVA ( $p=$ level of significance)

\begin{tabular}{llllll}
\hline & Sum of squares & df & Means of squares & F & Significance $\boldsymbol{p}$ value \\
\hline round & 0.4510 & 4 & 0.1128 & 1.9895 & 0.1123 \\
cross & 0.0223 & 4 & 0.0056 & 1.7829 & 0.1489 \\
$3 \mathrm{~mm}$ & 0.3803 & 4 & 0.0951 & 2.4797 & 0.0535 \\
$9 \mathrm{~mm}$ & 0.6049 & 4 & 0.1512 & 1.1932 & 0.3268 \\
band & 4.9617 & 2 & 2.4809 & 14.9751 & $<0.001$ \\
\hline
\end{tabular}

TABLE 4- Fracture strength means in $\mathrm{N}$

\begin{tabular}{|c|c|c|c|c|c|c|c|}
\hline \multicolumn{2}{|c|}{ joining configuration } & \multirow{2}{*}{$\frac{n}{10}$} & \multirow{2}{*}{$\begin{array}{l}\text { means } \\
384.0\end{array}$} & \multirow{2}{*}{$\begin{array}{l}\text { SD } \\
98.0\end{array}$} & \multirow{2}{*}{$\frac{\text { SE }}{31.0}$} & \multirow{2}{*}{$\begin{array}{r}\text { minimum } \\
252.4\end{array}$} & \multirow{2}{*}{$\begin{array}{r}\text { maximum } \\
533.9\end{array}$} \\
\hline round & solder & & & & & & \\
\hline & TIG 1 & 10 & 651.3 & 86.6 & 27.4 & 557.5 & 810.2 \\
\hline & TIG 2 & 10 & 791.5 & 137.5 & 43.5 & 576.4 & 959.8 \\
\hline & Laser 1 & 10 & 655.2 & 137.0 & 43.3 & 474.5 & 830.4 \\
\hline & Laser 2 & 10 & 803.9 & 137.3 & 43.4 & 631.0 & 1069.7 \\
\hline & overall & 50 & 657.2 & 191.9 & 27.1 & 252.4 & 1069.7 \\
\hline \multirow[t]{6}{*}{ cross } & solder & 10 & 185.9 & 36.0 & 11.4 & 139.2 & 242.9 \\
\hline & TIG 1 & 10 & 712.8 & 115.1 & 36.4 & 551.7 & 901.8 \\
\hline & TIG 2 & 10 & 613.9 & 206.0 & 65.2 & 361.8 & 948.8 \\
\hline & Laser 1 & 10 & 791.6 & 79.8 & 25.2 & 641.1 & 887.7 \\
\hline & Laser 2 & 10 & 794.4 & 231.0 & 73.0 & 406.2 & 1191.9 \\
\hline & overall & 50 & 619.7 & 271.8 & 38.4 & 139.2 & 1191.9 \\
\hline \multirow[t]{6}{*}{$3 \mathrm{~mm}$} & solder & 10 & 382.7 & 134.9 & 42.7 & 154.7 & 652.9 \\
\hline & TIG 1 & 10 & 725.0 & 104.2 & 33.0 & 488.2 & 867.7 \\
\hline & TIG 2 & 10 & 866.1 & 136.9 & 43.3 & 682.4 & 1082.2 \\
\hline & Laser 1 & 10 & 825.8 & 167.6 & 53.0 & 469.9 & 952.4 \\
\hline & Laser 2 & 10 & 997.9 & 281.7 & 89.1 & 517.6 & 1421.4 \\
\hline & overall & 50 & 759.5 & 269.4 & 38.1 & 154.7 & 1421.4 \\
\hline \multirow[t]{6}{*}{$9 \mathrm{~mm}$} & solder & 10 & 297.0 & 73.7 & 23.3 & 161.5 & 389.7 \\
\hline & TIG 1 & 10 & 548.9 & 105.3 & 33.3 & 461.3 & 783.4 \\
\hline & TIG 2 & 10 & 845.2 & 105.2 & 33.3 & 694.7 & 999.0 \\
\hline & Laser 1 & 10 & 687.6 & 112.8 & 35.7 & 484.1 & 878.1 \\
\hline & Laser 2 & 10 & 897.4 & 65.5 & 20.7 & 757.3 & 972.9 \\
\hline & overall & 50 & 655.2 & 237.1 & 33.5 & 161.5 & 999.0 \\
\hline \multirow[t]{4}{*}{ band } & solder & 10 & 406.7 & 116.1 & 38.7 & 210.0 & 595.6 \\
\hline & Laser 1 & 10 & 328.8 & 31.7 & 10.0 & 294.4 & 397.1 \\
\hline & Laser 2 & 10 & 441.3 & 34.6 & 10.9 & 381.7 & 491.8 \\
\hline & overall & 30 & 391.7 & 83.2 & 15.5 & 210.0 & 595.6 \\
\hline
\end{tabular}

have not been uniformly determined. The factors affecting the mechanical strength of welded joints have been described in different studies: wavelength, peak pulse power, pulse energy, output energy, pulse duration, pulse frequency and spot diameter of the laser-welding machine, and the type of metal used $d^{5,6,22-26}$.
Various authors have demonstrated changes in the welding area and the so-called heat-affected zone in Ni-CrMo, Co-Cr-Mo or titanium alloys depending on welding conditions $^{3,18}$. These authors pointed out that this is probably due to the different refining in the grain size and the substructure that appears during the rapid solidification 
TABLE 6- Results of Bonferroni post hoc test

\begin{tabular}{|c|c|c|c|c|c|c|c|c|c|c|c|}
\hline & & $\begin{array}{l}\text { round } \\
p=\end{array}$ & & $\begin{array}{l}\text { cross } \\
p=\end{array}$ & & $\begin{array}{l}3 \mathrm{~mm} \\
\mathrm{p}=\end{array}$ & & $\begin{array}{l}9 \mathrm{~mm} \\
p=\end{array}$ & & $\begin{array}{l}\text { band } \\
p=\end{array}$ & \\
\hline \multirow[t]{4}{*}{ solder } & TIG 1 & $<0.001$ & $\star \star \star *$ & $<0.001$ & $\star * *$ & $<0.001$ & $\star \star \star ~$ & $<0.001$ & $\star \star \star *$ & & \\
\hline & TIG 2 & $<0.001$ & $\star \star \star$ & $<0.001$ & $\star \star \star *$ & $<0.001$ & 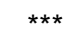 & $<0.001$ & 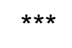 & & \\
\hline & Laser 1 & $<0.001$ & $\star \star \star *$ & $<0.001$ & $\star \star \star *$ & $<0.001$ & $\star \star \star *$ & $<0.001$ & 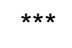 & 0.069 & ns \\
\hline & Laser 2 & $<0.001$ & $\star * *$ & $<0.001$ & $* \star *$ & $<0.001$ & $\star * *$ & $<0.001$ & $\star * \star$ & 0.876 & ns \\
\hline \multirow[t]{3}{*}{ TIG 1} & TIG 2 & 0.131 & ns & 1.000 & ns & 0.800 & ns & $<0.001$ & $\star \star \star *$ & & \\
\hline & Laser 1 & 1.000 & ns & 1.000 & ns & 1.000 & ns & 0.019 & * & & \\
\hline & Laser 2 & 0.073 & ns & 1.000 & ns & 0.012 & * & $<0.001$ & $\star \star \star$ & & \\
\hline \multirow[t]{2}{*}{ TIG 2} & Laser 1 & 0.157 & ns & 0.126 & ns & 1.000 & ns & 0.005 & * & & \\
\hline & Laser 2 & 1.000 & ns & 0.113 & ns & 1.000 & ns & 1.000 & ns & & \\
\hline Laser1 & Laser 2 & 0.088 & ns & 1.000 & ns & 0.342 & ns & $<0.001$ & 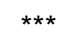 & 0.004 & ** \\
\hline
\end{tabular}

ns $=$ non significant; level of significance: $p<0.05^{*} . p<0.01{ }^{* \star} . p<0.001$ ***.

TABLE 5- Results of ANova ( $p=$ level of significance)

\begin{tabular}{llllll}
\hline & Sum of squares & df & Means of squares & F & Significance $\boldsymbol{p}$ value \\
\hline round & 1142310.4 & 4.000 & 285577.600 & 19.394 & $<0.001$ \\
cross & 2569065.4 & 4.000 & 642266.351 & 27.516 & $<0.001$ \\
$3 \mathrm{~mm}$ & 2157775.7 & 4.000 & 539443.920 & 17.374 & $<0.001$ \\
$9 \mathrm{~mm}$ & 2354418.2 & 4.000 & 588604.539 & 66.006 & $<0.001$ \\
band & 66184.3 & 2.000 & 33092.150 & 6.735 & 0.004 \\
\hline
\end{tabular}

stage. Wiskott, et al. ${ }^{27}$ (2001) found a correlation between definite increase in grain size and increased heat application in brazing, electric resistance and laser welding of Au-Pd alloy. However, the authors could not correlate the element analysis with the fracture strength of the specimens. Bertrand, et al. ${ }^{3}$ (2004) have observed that a small change in the chemical composition of the Ni-based alloys caused a very important difference in the weldability.

Accordingly, the results of other authors investigating laser-welded titanium indicated that, under the appropriate conditions, the joint strength of laser-welded titanium was not significantly different from the non-welded parent metal $^{4,9}$. In contrast to these findings, Watanbe and Topham ${ }^{25}$ (2004) did not achieve the same fracture load of non-welded Ti-, gold- or Co-Cr alloys in different configurations of laser welding. Specially for gold- and Co-Cr alloys only 50\% or less of the original measurements were obtained.

Babe, et al. ${ }^{2}$ (2004) found that the fracture strength for all laser-welded CoCr- alloy specimens tended to be lower than those for the controls. Depending on welding conditions the mean fracture force ranged from 224 to $622 \mathrm{~N}$ for singlewelded specimens and from 252 to $1292 \mathrm{~N}$ for the $1.0-\mathrm{mm}$ double welded specimens. Only at currents of 270 and $300 \mathrm{~A}$ significant differences could not be found from the results for the non-welded control specimens $(1733 \mathrm{~N})^{2}$.

Rocha, et al. ${ }^{11}$ (2006) compared laser and TIG welding of non precious alloys. TIG welding increased the flexural strength of $\mathrm{Ti}$, Co-Cr, Ni-Cr whereas the welded cylinders presented higher flexural strength than non-welded cylinders. The highest means were observed for Co-Cr weld by TIG and non-welded Co-Cr. In contrast, laser welding achieved only $17.5 \%$ of the flexural strength of Co-Cr alloy.

The controversial results of decreasing or increasing mechanical strength of welded precious and non-precious cast alloys were not found for orthodontic materials. Krishnan, et al. ${ }^{8}$ (2004) evaluated three orthodontic arch wire alloy materials - stainless steel, beta titanium and Timolium - as to their laser weld characteristics. Fracture strength differed significantly between the three materials (stainless steel $363 \pm 22 \mathrm{MPa}$, Beta titanium $463 \pm 27 \mathrm{MPa}$, Timolium $344 \pm 25 \mathrm{MPa}$ ). Although a comparison to original wires was missing in this study, it could be assumed that laser-welded specimens showed significant lower fracture strength than pure metals (approximately 1500-1800 MPa). These findings were in accordance to our results.

A recent study using additional filling material demonstrated higher flexural strength for Ti- $(+18 \%)$, NiCr(+66\%) and CoCr- (+69\%) laser welded alloys ${ }^{11}$. In the present study, the increase in fracture strength ranged from $16 \%$ and $35 \%$ in TIG- and laser welding. An additional benefit was observed.

In the present investigation, a direct comparison between 
brazing, TIG- and laser welding was performed for the first time. Brazing demonstrated the lowest mean fracture strength. Defects of our tests were equal to the clinical findings of complete ruptures without a real conjunction between two metal frameworks. TIG and laser welding showed significantly higher fracture strength means, but the tensile strength of original wire was not achievable. Therefore, welding changed the material attributes and the fact of missing spring hard quality has to be considered in planning of orthodontic appliances.

Testing the fracture strength, the brand new TIG welding appeared to be comparable to the laser welding method and is an interesting low cost and solder free alternative for orthodontic purposes. However, it should be highlighted that the impossibility to create band-to-wire joints limits the clinical use of TIG-welding in orthodontics. Further research is needed to determine the optimal welding parameters for each device and different joining methods, especially to joining orthodontic wires with orthodontic bands.

\section{CONCLUSION}

The use of additional filling material in TIG- and laser welding improved the mechanical behavior of orthodontic wire joint configuration and can be recommended for achieving higher fracture strength.

\section{REFERENCES}

1- Baba N, Watanabe I. Penetration depth into dental casting alloys by Nd:YAG laser. J Biomed Mater Res B Appl Biomater. 2005;72:648 .

2- Baba N, Watanabe I, Liu J, Atsuta M. Mechanical strength of laserwelded cobalt-chromium alloy. J Biomed Mater Res B Appl Biomater. 2004;69:121-4.

3- Bertrand C, le Petitcorps Y, Albingre L, Dupuis V. Optimization of operator and physical parameters for laser welding of dental materials. Br Dent J. 2004;196:413-8; discussion 07.

4- Chai T, Chou CK. Mechanical properties of laser-welded cas titanium joints under different conditions. J Prosthet Dent. 1998;79:477-83.

5- Dua R, Nandlal B. A comparative evaluation of the tensile strength of silver soldered joints of stainless steel and cobalt chromium orthodontic wires with band material - an in vitro study. J Indian Soc Pedod Prev Dent. 2004;22:13-6.

6- Heidemann J, Witt E, Feeg M, Werz R, Pieger K. Orthodontic soldering techniques: aspects of quality assurance in the dental laboratory. J Orofac Orthop. 2002;63:325-38.

7- Huang HH, Lin MC, Lin CC, Lin SC, Hsu CC, Chen FL, et al. Effects of welding pulse energy and fluoride ion on the cracking susceptibility and fatigue behavior of Nd:YAG laser-welded cast titanium joints. Dent Mater J. 2006;25:632-40.

8- Krishnan V, Kumar KJ. Weld characteristics of orthodontic archwire materials. Angle Orthod. 2004;74:533-8.
9- Liu J, Watanabe I, Yoshida K, Atsuta M. Joint strength of laserwelded titanium. Dent Mater. 2002;18:143-8.

10- Mockers O, Deroze D, Camps J. Cytotoxicity of orthodontic bands, brackets and archwires in vitro. Dent Mater. 2002;18:311-7.

11- Rocha R, Pinheiro AL, Villaverde AB. Flexural strength of pure Ti, Ni-Cr and Co-Cr alloys submitted to Nd:YAG laser or TIG welding. Braz Dent J. 2006;17:20-3.

12- Scroggs MW, Lewis JS, Proia AD. Corneal argyrosis associated with silver soldering. Cornea. 1992;11:264-9.

13- Sestini S, Notarantonio L, Cerboni B, Alessandrini C, Fimiani M, Nannelli P, et al. In vitro toxicity evaluation of silver soldering, electrical resistance, and laser welding of orthodontic wires. Eur J Orthod. 2006;28:567-72.

14- Solmi R, Martini D, Zanarini M, Isaza Penco S, Rimondini L, Carinci $\mathrm{P}$, et al. Interactions of fibroblasts with soldered and laserwelded joints. Biomaterials. 2004;25:735-40.

15- Srimaneepong V, Yoneyama T, Kobayashi E, Doi H, Hanawa T. Mechanical strength and microstructure of laser-welded Ti-6Al-7Nb alloy castings. Dent Mater J. 2005;24:541-9.

16- Tambasco J, Anthony T, Sandven O. Laser welding in the dental laboratory: an alternative to soldering. J Dent Technol. 1996;13:2331.

17- Taylor JC, Hondrum SO, Prasad A, Brodersen CA. Effects of joint configuration for the arc welding of cast Ti-6Al-4V alloy rods in argon. J Prosthet Dent. 1998;79:291-7.

18- Uysal H, Kurtoglu C, Gurbuz R, Tutuncu N. Structure and mechanical properties of Cresco-Ti laser-welded joints and stress analyses using finite element models of fixed distal extension and fixed partial prosthetic designs. J Prosthet Dent. 2005;93:235-44.

19- Verstrynge A, Van Humbeeck J, Willems G. In-vitro evaluation of the material characteristics of stainless steel and beta-titanium orthodontic wires. Am J Orthod Dentofacial Orthop. 2006;130:46070 .

20- Wang RR, Chang CT. Thermal modeling of laser welding for titanium dental restorations. J Prosthet Dent. 1998;79:335-41.

21- Watanabe I, Baba N, Chang J, Chiu Y. Nd:YAG laser penetration into cast titanium and gold alloy with different surface preparations. J Oral Rehabil. 2006;33:443-6.

22- Watanabe I, Liu J, Atsuta M. Effects of heat treatments on mechanical strength of laser-welded equi-atomic AuCu-6at\%Ga alloy. J Dent Res. 2001;80:1813-7.

23- Watanabe I, Liu J, Atsuta M, Okabe T. Effect of welding method on joint strength of laser-welded gold alloy. Am J Dent. 2003;16:2314

24- Watanabe I, Liu J, Baba N, Atsuta M, Okabe T. Optimizing mechanical properties of laser-welded gold alloy through heat treatment. Dent Mater. 2004;20:630-4.

25- Watanabe I, Topham DS. Tensile strength and elongation of laser-welded Ti and Ti-6AL-7NB. J Biomed Mater Res B Appl Biomater. 2004;71:46-51.

26- Watanabe I, Topham DS. Laser welding of cast titanium and dental alloys using argon shielding. J Prosthodont. 2006;15:102-7. 
27- Wiskott HW, Doumas T, Scherrer SS, Belser UC, Susz C. Mechanical and structural characteristics of commercially pure grade 2 Ti welds and solder joints. J Mater Sci Mater Med. 2001;12:71925

28- Yan XJ, Yang DZ. Corrosion resistance of a laser spot-welded joint of NiTi wire in simulated human body fluids. J Biomed Mater Res A. 2006;77:97-102.

29- Yokota K, Minami T, Michitsuji H, Fujio T, Yamada S. Occupational dermatitis from soldering flux. Ind Health. 2004;42:383-4

30- Zupancic R, Legat A, Funduk N. Tensile strength and corrosion resistance of brazed and laser-welded cobalt-chromium alloy joints. J Prosthet Dent. 2006;96:273-82. 